\title{
Types of Stove in Use and Respiratory and Eye Health of Nepal Rural Housewives: A Cross- Sectional Study
}

\section{Changwoo Han}

Chungnam National University School of Medicine

\section{Seshananda Sanjel}

Dhulikhel Hospital

\section{Prabin Shakya}

Dhulikhel Hospital

\section{Woo-Seok Lee}

Seoul National University College of Medicine

\section{Woo-Sung Kim}

Seoul National University College of Medicine

\section{Biraj Karmacharya \\ Dhulikhel Hospital}

\section{Biraj Neupane}

Dhulikhel Hospital

Yun-Chul Hong ( $\nabla$ ychong1@snu.ac.kr)

Seoul National University College of Medicine

\section{Research article}

Keywords: Nepal, gas stove, respiratory health, eye health

Posted Date: September 10th, 2020

DOI: https://doi.org/10.21203/rs.3.rs-34858/v1

License: (c) (1) This work is licensed under a Creative Commons Attribution 4.0 International License. Read Full License 


\section{Abstract}

\section{Backgrounds}

Health benefits of energy transition from solid fuels to cleaner fuels can be evaluated in field study of developing countries. Even a simple cross-sectional studies may be useful for estimation of the health benefits. This study was conducted in rural Nepal with the hypothesis that the gas stove and clean fuel users may have better respiratory and eye health compared to traditional stove and solid fuel users due to the low household air pollution levels.

\section{Methods}

From July to August 2018, we recruited 90 housewives who resided in a rural Nepal village (Nuwakot District, Likhu Municipality). We conducted a questionnaire survey, physical examination, blood test, and 24-hour monitoring of particulate matter less than $2.5 \mu \mathrm{m}$ in diameter $\left(\mathrm{PM}_{2.5}\right)$ levels in kitchen. Logistic regression analysis was used to evaluate the association of types of stove used in kitchens with respiratory and eye symptoms in housewives.

\section{Results}

Of 90 participants, 42 and 43 used traditional and gas stove as their primary stove, respectively. Over $28 \%$ and $75 \%$ of participants experienced mild to moderate airway obstruction and watery eye symptoms during cooking. The odds ratios (95\% confidence interval) of chronic cough $[0.30(0.05,1.86)]$, wheezing $[0.30(0.06,1.49)]$, phlegm $[0.36(0.08,1.53)]$, shortness of breath $[0.81(0.31,2.09)]$, high chronic obstructive pulmonary disease assessment test scores $[0.36(0.10,1.30)]$, and watery eye symptoms during cooking $[0.14(0.04,0.51)]$ were lower in gas stove users compared to the traditional stove users. The average 24-hour kitchen $\mathrm{PM}_{2.5}$ concentrations were lower in gas stove user houses $\left(11 \mu \mathrm{g} / \mathrm{m}^{3}\right)$ than in traditional stove user houses $\left(33 \mu \mathrm{g} / \mathrm{m}^{3}\right)$.

\section{Conclusions}

Gas stove and clean fuel use may be beneficial for reducing eye discomfort during cooking. Further longitudinal and intervention studies are needed to conclude whether the transition from solid fuels to cleaner fuels will be beneficial for the respiratory and eye health of Nepalese housewives.

\section{Background}

The World Health Organization estimated that globally over 3.8 million deaths due to acute lower respiratory infections, chronic obstructive pulmonary disease (COPD), lung cancer, ischemic heart disease, and stroke were attributable to household air pollution exposure, which originates from use of solid fuels (coal, wood, charcoal, dung, crop residues, and kerosene) and high polluting traditional stoves [1]. Energy transition from solid fuels to cleaner fuels (liquefied petroleum gas, biogas, alcohol fuels) are 
regarded as useful methods for reducing household air pollution levels, but there are still limited number of studies evaluating the health benefits of energy transition [2]. Prospective intervention studies regarding energy transition and co-benefits of health may generate causal evidences, but they are costly as well as time-consuming. Therefore, for the interim estimation of the health benefits of energy transition and suggestion of cost-effective interventions, well-designed cross-sectional baseline studies are needed in regions where use of solid fuels and traditional stoves are prevalent.

Nepal is one of the poorest countries where more than $66 \%$ of the household uses traditional stoves and solid fuels [3]. COPD, one of the disease associated with household air pollution exposure, is estimated to be the second leading cause of death (9.84\% of total deaths) and one of the most common outpatient hospital visit causes in Nepal [4-6]. Continuous exposure to the high concentration of solid fuel smoke may induce inflammation and oxidative stress to respiratory epithelial cells, which leads to airway obstruction and disruption of the lung tissue $[7,8]$. In addition, oxidative stress may induce lens opacification, leading to cataract $[9,10]$. According to a recent health survey in Nepal, $2.3 \%$ of women aged over 50 years had bilateral blindness, and over $62 \%$ of these cases were due to cataract [11]. Not only cataract but also eye irritation and watery eye symptoms are expected after exposure to high levels of household air pollution.

By pooling 23 cross-sectional, case-control, and cohort studies; domestic use of solid fuel showed a 2.96 and 2.32 times increased risks of COPD and chronic bronchitis, respectively [12]. A study in a traditional village in Nepalese Himalayas reported association between early pulmonary impairment and household air pollution exposure [13]. In a cross-sectional study of 841 rural Mexican women, use of biomass fuel was associated with increased risks of respiratory symptoms and higher kitchen particulate matter concentration, compared with gas fuel use [14]. In a community-based cross-sectional study involving 157 Nepalese housewives, the most frequently reported health problem related to household air pollution was tearing eyes, followed by breathlessness and productive coughing [15]. By comparing household air pollution concentration in 824 households in rural Nepal, average particulate matter less than $2.5 \mu \mathrm{m}$ in diameter $\left(\mathrm{PM}_{2.5}\right)$ concentrations were lower in households using kerosene $\left(169 \mu \mathrm{g} / \mathrm{m}^{3}\right)$, gas $\left(101 \mu \mathrm{g} / \mathrm{m}^{3}\right)$, and electricity $\left(80 \mu \mathrm{g} / \mathrm{m}^{3}\right)$, compared to households using solid fuels $\left(656 \mu \mathrm{g} / \mathrm{m}^{3}\right)$ [16].

Therefore, it is plausible to hypothesize that a relationship exists between types of fuels in use and respiratory and eye health of Nepalese. In particular, due to the prolonged time activity patterns near cooking stoves, household air pollution may seriously affect the respiratory and eye health of Nepalese housewives. The similar COPD prevalence rates reported across sexes despite the higher smoking rate among men may represent higher household air pollution exposure in rural Nepal housewives [15, 17]. In addition, a population-based study in India showed an association between an increased risk of cataract and biomass fuel use in women but not in men [18]. However, there are limited number of studies comparing respiratory and eye health status of rural Nepalese housewives by types of fuels and stoves used in the household. 
Therefore, we conducted a small field study to evaluate the association between kitchen environment and respiratory and eye health of housewives residing in rural Nepal. We evaluated the kitchen environment and chronic respiratory symptoms by using structured questionnaires, COPD assessment test, and spirometer test. We measured the 24-hour kitchen $\mathrm{PM}_{2.5}$ concentrations and asked the housewives about watery eye symptoms during cooking and previous eye disease history. We regarded household with gas stove uses clean fuel and household with traditional stove uses solid fuels. Our study hypothesis was that the use of gas stove, compared to traditional stove, may be beneficial for respiratory and eye health due to decreased concentration of household air pollution.

\section{Methods}

\subsection{Study population and data collection}

From July to August 2018, we recruited 90 participants out of 300 housewives who were residing in Nuwakot District, Likhu Rural Municipality, Ward Number 5 and 6, Nepal. A convenience sampling approach was used in selecting the study site and participants, with a suggestion by the department of community program, Kathmandu medical school. Study participants' houses were within walkable distances from Dhulikhel hospital outreach center. Due to the location of the houses concentrated in small mountain villages far away from the urban city, we hypothesized that participants were homogenous in terms of lifestyle and socioeconomic status. The inclusion criteria for this study were housewives aged over 18 years who chose to participate in the project after understanding the process, advantages, and disadvantages of the study enrollment. The participants who refused to participate or who did not give informed consent, were participating in another study or pregnant, and anyone with severe cognitive impairments were excluded from the study. The general information (age, marital status, ethnicity, educational status, religion, job, and socioeconomic status), hospital use and past medical history (hypertension, diabetes, COPD, stroke, hyperlipidemia, and eye disease), personal habits (smoking, second-hand smoking, and drinking), kitchen environment (number of kitchen windows, types of stoves and fuels, availability of chimney, and reasons for selecting stoves and fuels), and chronic symptoms related to respiratory and eye disease were evaluated using the structured questionnaires. Physical examination and blood laboratory tests were conducted over two days (August 15-16, 2018). The questionnaire survey was conducted by Nepalese researchers and assistants using tablet personal computers (PCs). The Institutional Review Committee of Kathmandu University School of Medical Sciences/Dhulikehl Hospital (approval number: 84/18) and the Nepal Health Research Council Ethical Review Board (reg.no. 251/2018) approved this study.

\subsection{Physical examination and blood tests}

Trained heath care workers measured height, weight, waist circumference, and conducted pulmonary function test for the study participants. Height and weight were measured using portable stadiometer and calibrated balance beam scale (Giant-150N; Hana, Seoul, Korea), respectively. Body mass index (BMI) was calculated as weight in kilograms divided by height in meter square. Waist circumference was 
measured at the end of the normal expiration by measuring the lower borders of the rib cage and the iliac crest. We used Pony turbine spirometer (Cosmed USA, Inc., Chicago, IL) for the pulmonary function tests, following the American Thoracic Society guideline [19]. We calibrated the devices once daily before the examination and used disposable mouth-piece for each participant. The pulmonary function test was demonstrated by the research assistants prior to each test. The Korean researchers (medical doctors) conducted the pulmonary function tests while trained Nepalese research assistants with medicine or nursing backgrounds performed the translation.

In total, $5 \mathrm{~mL}$ of the venous blood was sampled from each study participant by a trained Nepalese nurse. Sampled blood was immediately centrifuged and stored at $-80^{\circ} \mathrm{C}$. The sample was transported from the outreach center to the Dhulikhel hospital for the analysis of glucose, lipid profile (total cholesterol, triglyceride, and high density lipoprotein cholesterol), liver enzyme (aspartate and alanine aminotransferase), kidney function (blood urea nitrogen and creatinine), inflammation (high sensitivity creactive protein, uric acid, and white blood cell counts), and anemia (hemoglobin).

\subsection{The 24-hour kitchen particulate matter monitoring}

The study participants' household kitchen particulate matter concentration was monitored by portable particulate matter measurement device (Aeroset 831 Met One Instruments, Inc) from August 15 to October 15, 2018. Research assistants visited the study participants' households in the morning and installed the device in the kitchen before 9 AM (1 m above the ground and $1 \mathrm{~m}$ away from the cooking stove). The assistant revisited the household to retrieve the device after ensuring at least 24 hours of monitoring time. However, of two monitoring devices, one malfunctioned since the second day of the measurement. Therefore, we were only able to retrieve the monitoring data of one device, which monitored 28 households ( 13 households with traditional stove and 15 household with gas stove). We hypothesized that the contribution of outdoor $\mathrm{PM}_{2.5}$ to the kitchen $\mathrm{PM}_{2.5}$ was minimal due to the far away location of our study site from major roads or industrial factories.

\subsection{Other variables}

We used the American Thoracic Society Division of Lung Disease questionnaire (ATS-DLD-78-A) to access cough, phlegm, episode of cough and phlegm, wheezing, breathlessness, chest colds, and chest illness [20]. COPD assessment test (CAT) was used to access for symptoms related to COPD [21]. Characteristics of the house (number of rooms, wall, floor, and roofing materials), kitchen environments (number of kitchen windows, types of stoves and fuels, availability of chimney, and reasons for selecting stoves and fuels) and watery eye symptoms during cooking were assessed using the World Bank household air pollution district survey questionnaire developed previously [22]. For the general information, hospital use and past medical history, and personal habits, we used the questionnaire for the Dhulikhel heart study developed by the Kathmandu University School of Medical Sciences [23]. All the questionnaire surveys were conducted by Nepalese research assistants using tablet PCs.

\subsection{Statistical analysis}


We compared the general characteristics of the study participants by the types of stove (gas versus traditional stove) used in households, using chi-square and t-test. We used logistic regression analysis to evaluate association between types of stove used in households and chronic respiratory and eye symptoms. Two models were selected for our main analysis. In model 1, we adjusted for age and variables, which showed significant differences $(p$-value $<0.1)$ between gas and traditional stove users in bivariate analysis (smoking status, smoking years, second-hand smoking, drinking history, and number of kitchen windows). In model 2, we adjusted for all the variables, which might confound the association (variables used in model 1 + educational status, schooling years, household income, and kitchen cross ventilation status). Because tobacco smoking is regarded as the most important factor for COPD pathogenesis [24], we conducted a sensitivity analysis by restricting the study participants to never smokers.

The means and standard deviations of average 24 hour $\mathrm{PM}_{2.5}$ concentrations (by calculating the 24-hour average value for each household) were compared according to the kitchen environment (number of windows, kitchen cross ventilation, and stove type) using linear regression analysis. All the analyses were conducted with SAS version 9.4 (SAS Institute Inc., Cary, NC, USA) and R statistical software (version 3.6.1; R Foundation for Statistical Computing, Vienna, Austria). The level of statistical significance was set at a p-value of less than 0.05 .

\section{Results}

Table 1 and Additional file 1 show the baseline characteristics, kitchen environments, and respiratory symptoms of study participants and the detailed questionnaires for respiratory and watery eye symptoms used in this study. Average age and monthly household income of the study participants were 40.1 years and 15,085 NPR (equal to 131 USD), respectively. About $67 \%$ of study participants could read and write, and had an average years of schooling of 5.5 years. Nearly $77 \%$ had never used tobacco products while $52 \%$ reported second-hand smoke exposure. In addition, $81 \%$ had no alcoholic beverages during the last 12 months before the study enrollment. Over $13 \%$ were suffering from chronic cough and wheezing. Nearly $24 \%$ were suffering from COPD symptoms in everyday life while $76 \%$ experienced watery eyes during cooking. The spirometer test revealed $29 \%$ as having mild to severe respiratory obstruction [Forced Expiratory Volume in 1 minute (FEV1)/Forced Vital Capacity $(\mathrm{FVC})<80 \%]$. 
Table 1

Baseline characteristics of study participants $(\mathrm{N}=90)$ and their household kitchen environment $N(\%)$ or Mean (SD)

$\begin{array}{llll}\text { Total }(\mathrm{n} & \begin{array}{l}\text { Traditional } \\ =90)\end{array} & \text { Gas } & \mathrm{p} \text { - } \\ & \text { stove }(\mathrm{n}= & \text { stove }(\mathrm{n} & \begin{array}{l}\text { value } \\ =43)\end{array} \\ & 47) & \text { a) }\end{array}$

Mean age (years)

40.1

(12.4)

Never

married/separated/widowed

Married

Average monthly

family income (NPR)

Literacy

Literate

Illiterate

Average years of

schooling (years)

Smoking status

Average years of

smoking

Second-hand smoking

\begin{tabular}{|c|c|c|c|c|}
\hline & $\begin{array}{l}15085.6 \\
(13348)\end{array}$ & $\begin{array}{l}13723.4 \\
(9933.9)\end{array}$ & $\begin{array}{l}16574.6 \\
(16282.6)\end{array}$ & 0.32 \\
\hline Literate & $\begin{array}{l}60 \\
(66.7)\end{array}$ & $30(63.8)$ & $30(69.8)$ & 0.66 \\
\hline \multirow[t]{2}{*}{ Illiterate } & $\begin{array}{l}30 \\
(33.3)\end{array}$ & $17(36.2)$ & $13(30.2)$ & \\
\hline & $\begin{array}{l}5.5 \\
(4.1)\end{array}$ & $4.7(3.8)$ & $6.2(4.3)$ & 0.16 \\
\hline Non-smoker & $\begin{array}{l}69 \\
(76.7)\end{array}$ & $32(68.1)$ & $37(86.1)$ & 0.04 \\
\hline \multirow[t]{2}{*}{ Past-smoker/Smoker } & $\begin{array}{l}21 \\
(23.3)\end{array}$ & $15(31.9)$ & $6(14.0)$ & \\
\hline & $\begin{array}{l}8.3 \\
(16.7)\end{array}$ & $12.1(19.7)$ & $4.2(11.4)$ & 0.02 \\
\hline No & $\begin{array}{l}43 \\
(47.8)\end{array}$ & $18(38.3)$ & $25(58.1)$ & 0.06 \\
\hline
\end{tabular}

a) Chi square tests were conducted for categorical variables and t-tests were conducted for continuous variables

b) Results from the Fisher's exact test

c) Overweight: $25 \leq \mathrm{BMI}<30$; Overweight: $30 \leq \mathrm{BMI}$

d) Abdominal obese, Normal: Waist circumference < 80; Obese: $80 \leq$ Waist circumference

e) COPD assessment test, Low: score < 10; Medium to very high: $10 \leq$ score

f) Airway obstruction, Normal: $80 \leq$ FEV1/FVC; Mild to severe obstruction: FEV1/FVC $<80$ 


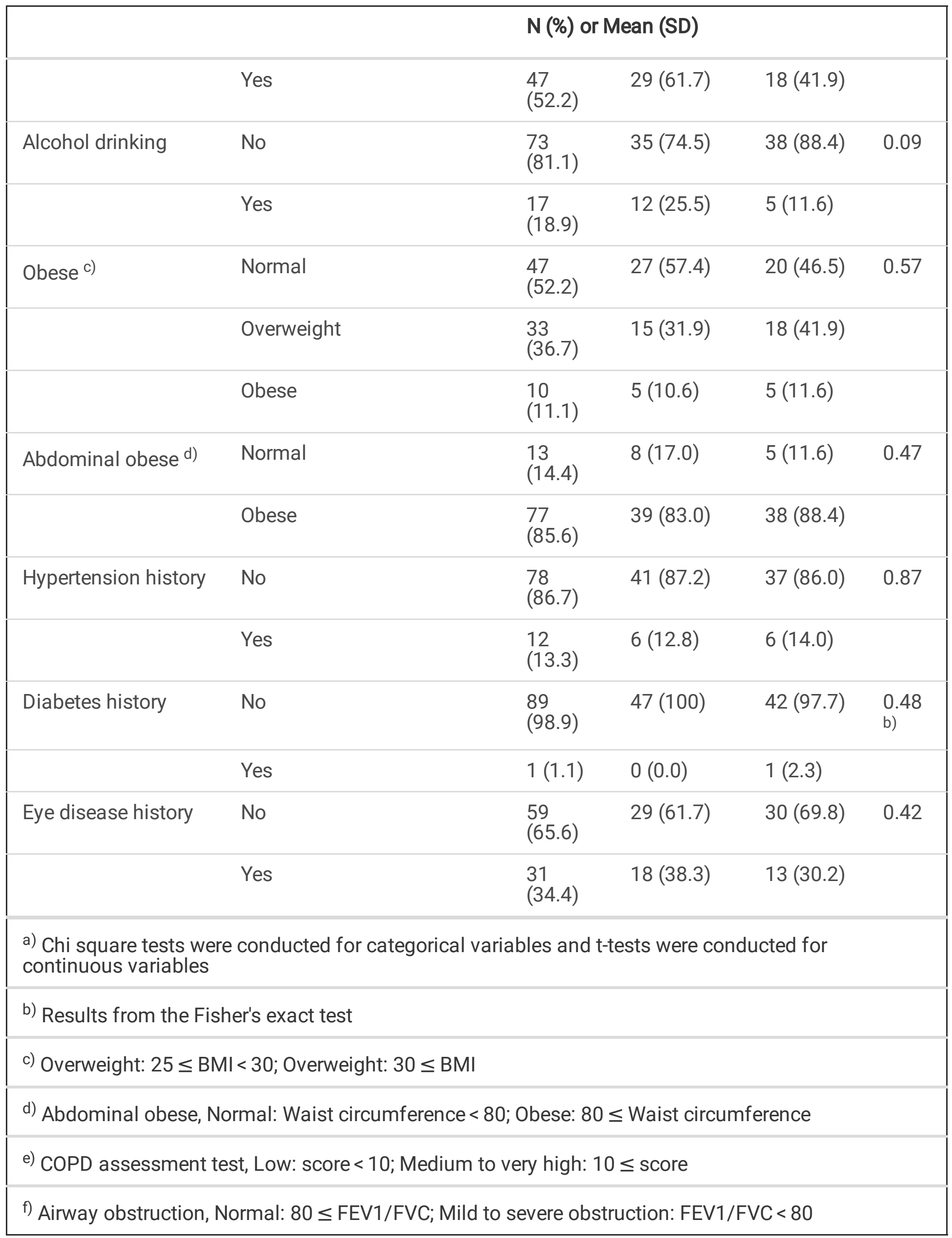




\begin{tabular}{|c|c|c|c|c|c|}
\hline \multirow[b]{2}{*}{$\begin{array}{l}\text { Number of windows } \\
\text { (kitchen) }\end{array}$} & \multirow[b]{2}{*}{0} & \multicolumn{2}{|c|}{ N (\%) or Mean (SD) } & \multirow[b]{2}{*}{$11(25.6)$} & \multirow[b]{2}{*}{0.09} \\
\hline & & $\begin{array}{l}28 \\
(31.1)\end{array}$ & $17(36.2)$ & & \\
\hline & 1 & $\begin{array}{l}40 \\
(44.4)\end{array}$ & $23(48.9)$ & $17(39.5)$ & \\
\hline & $2+$ & $\begin{array}{l}22 \\
(24.4)\end{array}$ & $7(14.9)$ & $15(34.9)$ & \\
\hline \multirow[t]{2}{*}{$\begin{array}{l}\text { Kitchen cross } \\
\text { ventilation }\end{array}$} & No & $\begin{array}{l}68 \\
(75.6)\end{array}$ & $38(80.9)$ & $30(69.8)$ & 0.22 \\
\hline & Yes & $\begin{array}{l}22 \\
(24.4)\end{array}$ & $9(19.1)$ & $13(30.2)$ & \\
\hline \multirow[t]{2}{*}{ Roof in the kitchen } & No & $\begin{array}{l}87 \\
(96.7)\end{array}$ & $44(93.6)$ & $43(100)$ & $\begin{array}{l}0.24 \\
\text { b) }\end{array}$ \\
\hline & Yes & $3(3.3)$ & $3(6.4)$ & $0(0)$ & \\
\hline \multicolumn{2}{|l|}{ Age started cooking } & $\begin{array}{l}12.7 \\
(3.7)\end{array}$ & $12.9(3.1)$ & $12.5(4.3)$ & 0.63 \\
\hline \multicolumn{2}{|l|}{$\begin{array}{l}\text { Average time in } \\
\text { kitchen }\end{array}$} & $\begin{array}{l}3.1 \\
(2.0)\end{array}$ & $2.8(0.8)$ & $3.4(2.7)$ & 0.16 \\
\hline \multirow[t]{2}{*}{ Chronic coughing } & No & $\begin{array}{l}78 \\
(86.7)\end{array}$ & 37 (78.7) & $41(95.3)$ & 0.02 \\
\hline & Yes & $\begin{array}{l}12 \\
(13.3)\end{array}$ & $10(21.3)$ & $2(4.7)$ & \\
\hline \multirow[t]{2}{*}{ Wheezing } & No & $\begin{array}{l}78 \\
(86.7)\end{array}$ & $38(80.9)$ & $40(93.0)$ & 0.09 \\
\hline & Yes & $\begin{array}{l}12 \\
(13.3)\end{array}$ & $9(19.1)$ & $3(7.0)$ & \\
\hline Phlegm & No & $\begin{array}{l}73 \\
(81.1)\end{array}$ & $34(72.3)$ & $39(90.7)$ & 0.03 \\
\hline \multicolumn{6}{|c|}{$\begin{array}{l}\text { a) Chi square tests were conducted for categorical variables and t-tests were conducted for } \\
\text { continuous variables }\end{array}$} \\
\hline \multicolumn{6}{|c|}{ b) Results from the Fisher's exact test } \\
\hline \multicolumn{6}{|c|}{ c) Overweight: $25 \leq \mathrm{BMI}<30$; Overweight: $30 \leq \mathrm{BMI}$} \\
\hline \multicolumn{6}{|c|}{ d) Abdominal obese, Normal: Waist circumference < 80; Obese: $80 \leq$ Waist circumference } \\
\hline \multicolumn{6}{|c|}{ e) COPD assessment test, Low: score < 10; Medium to very high: $10 \leq$ score } \\
\hline \multicolumn{6}{|c|}{ f) Airway obstruction, Normal: $80 \leq$ FEV1/FVC; Mild to severe obstruction: FEV1/FVC < 80} \\
\hline
\end{tabular}




\begin{tabular}{|c|c|c|c|c|c|}
\hline & & $N(\%) 0$ & ean (SD) & & \\
\hline & Yes & $\begin{array}{l}17 \\
(18.9)\end{array}$ & $13(27.7)$ & $4(9.3)$ & \\
\hline Shortness of breath & No & $\begin{array}{l}44 \\
(48.9)\end{array}$ & $21(44.7)$ & $23(53.5)$ & 0.40 \\
\hline & Yes & $\begin{array}{l}46 \\
(51.1)\end{array}$ & $26(55.3)$ & $20(46.5)$ & \\
\hline $\begin{array}{l}\text { COPD assessment } \\
\text { test } e^{\text {) }}\end{array}$ & Low & $\begin{array}{l}68 \\
(75.6)\end{array}$ & $31(66.0)$ & 37 (86.0) & 0.03 \\
\hline & Medium to very high & $\begin{array}{l}22 \\
(24.4)\end{array}$ & $16(34.0)$ & $6(14.0)$ & \\
\hline $\begin{array}{l}\text { Airway obstruction f) } \\
\text { (FEV1/FVC) (P/Ex) }\end{array}$ & Normal & $\begin{array}{l}64 \\
(71.1)\end{array}$ & $31(66.0)$ & $33(76.7)$ & 0.26 \\
\hline & Mild to severe obstruction & $\begin{array}{l}26 \\
(28.9)\end{array}$ & $16(34.0)$ & $10(23.3)$ & \\
\hline $\begin{array}{l}\text { Watery eyes during } \\
\text { cooking }\end{array}$ & No & $\begin{array}{l}22 \\
(24.4)\end{array}$ & $5(10.6)$ & $17(39.5)$ & $\begin{array}{l}< \\
0.01\end{array}$ \\
\hline & Yes & $\begin{array}{l}68 \\
(75.6)\end{array}$ & $42(89.4)$ & $26(60.5)$ & \\
\hline $\begin{array}{l}\text { a) Chi square tests we } \\
\text { continuous variables }\end{array}$ & conducted for categorical v & les and & sts were co & cted for & \\
\hline b) Results from the Fi & er's exact test & & & & \\
\hline c) Overweight: $25 \leq \mathrm{B}$ & < 30; Overweight: $30 \leq \mathrm{BMI}$ & & & & \\
\hline d) Abdominal obese, I & mal: Waist circumference < & Obese: 8 & Waist circu & erence & \\
\hline e) COPD assessment & t, Low: score < 10; Medium & ry high: & $\leq$ score & & \\
\hline f) Airway obstruction, & rmal: $80 \leq$ FEV1/FVC; Mild & evere ob & ction: FEV1 & $C<80$ & \\
\hline
\end{tabular}

Of 90 housewives, 47 and 43 used traditional and gas stove as their primary stoves, respectively. There were more smokers, second-hand smokers, and drinkers among traditional stove users while more windows were observed in gas stove users' kitchens. The gas stove users showed reduced risk of chronic cough, wheezing, phlegm, and watery eye symptoms during cooking and lower COPD assessment test scores. Additional file 2 shows the blood test results of the study participants. About $30 \%$ and $91 \%$ of study participants showed abnormal levels of triglycerides (>150 mg/dL) and high-density lipoprotein cholesterol ( $\leq 60 \mathrm{mg} / \mathrm{dL}$ ). Nearly $33 \%$ had high levels of blood urea nitrogen ( $\geq 20 \mathrm{mg} / \mathrm{dL}$ ) while $51 \%$ 
showed high levels of high-sensitivity C-reactive protein ( $\geq 0.5 \mathrm{mg} / \mathrm{dL})$. In addition, $18 \%$ were diagnosed with anemia (blood hemoglobin levels $<12 \mathrm{~g} / \mathrm{dL}$ ). Although the blood triglyceride levels were slightly higher in gas stove users, there was no differences in other biomarkers between gas and traditional stove users.

Table 2 shows the odds ratios (ORs) and $95 \%$ confidence intervals $(95 \% \mathrm{Cl})$ of the respiratory and eye symptoms of housewives according to the types of stove used in the household. Compared to the traditional stove users, gas stove users showed decreased risk of chronic respiratory symptoms [OR $(95 \% \mathrm{Cl})$ cough: $0.30(0.05,1.86)$; wheezing: $0.30(0.06,1.49)$; phlegm: $0.36(0.08,1.53)$; and shortness of breath: $0.81(0.31,2.09)]$, eye disease history [OR $(95 \% \mathrm{Cl}): 0.48(0.17,1.38)]$, and medium to very high COPD assessment test scores [OR $(95 \% \mathrm{Cl}): 0.36(0.10,1.30)$ ], although the results were not statistically significant. The risk estimates for mild-to-severe obstruction in the pulmonary function test results did not differ by the type of stove used. However, the risk of watery eye symptoms [OR $(95 \% \mathrm{Cl}): 0.14(0.04,0.52)$ ] during cooking was significantly lower in gas stove users than in traditional stove users. We observed similar results when we restricted our analysis to non-smokers in sensitivity analysis (shown in Additional file 3). 
Table 2

Risks (odds ratio) of respiratory and watery eye symptoms according to primary stove types

\begin{tabular}{|c|c|c|c|c|}
\hline & \multirow[t]{2}{*}{$\begin{array}{l}\text { Traditional } \\
\text { stove }\end{array}$} & \multicolumn{3}{|l|}{ Gas stove } \\
\hline & & Crude model & Model 1 a) & Model 2 b) \\
\hline Chronic coughing & ref & $\begin{array}{l}0.18 \\
(0.04,0.88)\end{array}$ & $0.26(0.04,1.55)$ & $0.30(0.05,1.86)$ \\
\hline Wheezing & ref & $\begin{array}{l}0.32 \\
(0.08,1.26)\end{array}$ & $0.32(0.07,1.46)$ & $0.30(0.06,1.49)$ \\
\hline Phlegm & ref & $\begin{array}{l}0.27 \\
(0.08,0.90)\end{array}$ & $0.37(0.10,1.37)$ & $0.36(0.08,1.53)$ \\
\hline Shortness of breath & ref & $\begin{array}{l}0.70 \\
(0.31,1.61)\end{array}$ & $0.80(0.32,2.00)$ & $0.81(0.31,2.09)$ \\
\hline COPD assessment test & ref & $\begin{array}{l}0.31 \\
(0.11,0.90)\end{array}$ & $0.32(0.09,1.07)$ & $0.36(0.10,1.30)$ \\
\hline $\begin{array}{l}\text { Airway obstruction } \\
(\mathrm{P} / \mathrm{Ex})\end{array}$ & ref & $\begin{array}{l}0.59 \\
(0.23,1.49)\end{array}$ & $1.01(0.33,3.08)$ & $0.99(0.27,3.65)$ \\
\hline Eye disease history & ref & $\begin{array}{l}0.70(0.29 \\
0.68)\end{array}$ & $\begin{array}{l}0.53(0.19 \\
1.45)\end{array}$ & $\begin{array}{l}0.48(0.17 \\
1.38)\end{array}$ \\
\hline Watery eyes & ref & $\begin{array}{l}0.18 \\
(0.06,0.55)\end{array}$ & $0.18(0.06,0.60)$ & $0.14(0.04,0.52)$ \\
\hline \multicolumn{5}{|c|}{$\begin{array}{l}\text { a) Model 1: adjusted for age, smoking status, smoking years, drinking history, second-hand smoking, } \\
\text { and number of kitchen windows }\end{array}$} \\
\hline $\begin{array}{l}\text { b) Model 2: Model } 1+\mathrm{ec} \\
\text { ventilation status }\end{array}$ & nal statu & ing years, ho & d income, and & hen cross \\
\hline
\end{tabular}

Table 3, Fig. 1, and Additional file 4 shows the daily concentration of $\mathrm{PM}_{2.5}$ by kitchen environments among 28 monitored households (13 households with traditional stove and 15 households with gas stove). The average 24-hour $\mathrm{PM}_{2.5}$ concentration was $22 \mu \mathrm{g} / \mathrm{m}^{3}$. Compared to traditional stove-using households, gas stove-using households showed - $22(95 \% \mathrm{Cl}:-34,-9) \mu \mathrm{g} / \mathrm{m}^{3}$ lower average $\mathrm{PM}_{2.5}$ concentrations. By evaluating time-concentration patterns, kitchen $\mathrm{PM}_{2.5}$ concentrations increased between 5 and $9 \mathrm{AM}$, and between 5 and 8 PM in traditional stove-using households, showing high variability of $\mathrm{PM}_{2.5}$ concentrations compared to gas stove households. As shown in Fig. 1, households with gas stove did not show marked increase in $\mathrm{PM}_{2.5}$ concentrations during these periods unlike the traditional stove-using households. 
Table 3

Means and standard deviations (SDs) of the average 24-hour $\mathrm{PM}_{2.5}$ concentration according to kitchen environment. Analyses were conducted in households with 24-hour $\mathrm{PM}_{2.5}$ measurements $(\mathrm{N}=28)$.

\begin{tabular}{|c|c|c|c|c|}
\hline & & $\mathbf{N}$ & $\begin{array}{l}\text { Mean (SD) } \\
\text { of the average } \\
\text { 24-hour } \mathrm{PM}_{2.5} \text { concentration } \\
\left(\mu \mathrm{g} / \mathrm{m}^{3}\right)\end{array}$ & $\begin{array}{l}\text { Differences } \\
\text { a) } \\
\left(\mu \mathrm{g} / \mathrm{m}^{3}\right)\end{array}$ \\
\hline $\begin{array}{l}\text { Total } \\
\text { household }\end{array}$ & & 28 & $22(20)$ & \\
\hline \multirow[t]{3}{*}{$\begin{array}{l}\text { Number of windows } \\
\text { (kitchen) }\end{array}$} & 0 & 6 & $21(12)$ & Ref \\
\hline & 1 & 13 & $22(18)$ & $1(-19,20)$ \\
\hline & $2+$ & 9 & $21(29)$ & $0(-20,21)$ \\
\hline \multirow[t]{2}{*}{ Kitchen cross ventilation } & No & 21 & $21(15)$ & Ref \\
\hline & Yes & 7 & $22(34)$ & $1(-16,18)$ \\
\hline \multirow[t]{2}{*}{ Primary stove type } & Traditional & 13 & $33(25)$ & Ref \\
\hline & Gas & 15 & $11(4)$ & $\begin{array}{l}-22(-34,-9) \\
\text { b) }\end{array}$ \\
\hline \multicolumn{5}{|c|}{ a) Differences were calculated using linear regression analysis } \\
\hline b) p-value below 0.05 & & & & \\
\hline
\end{tabular}

Additional file 5 shows the participants' reasons for selecting the primary stove and fuels. Nearly $70 \%$ of participants selected their primary stove based on convenience (42\%) and economic reasons (29\%). Most of the participants (97\%) had never changed their primary stove. In addition, although clean fuel such as liquefied petroleum gas (LPG), liquefied natural gas (LNG), and electricity were largely available, participants did not use them due to economic and convenience reasons.

\section{Discussion}

In our field study in rural Nepal, the use of gas stove was associated with a decrease in watery eye symptoms in housewives. The risk estimates for chronic cough, wheezing, phlegm, sputum, and previous diagnosis of eye disease decreased in housewives using gas stoves compared to that in traditional stove users, but the results were not statistically significant. The risk of eye discomfort as well as 24-hour $\mathrm{PM}_{2.5}$ levels were significantly lower in gas stove-using households than in traditional stove-using households. 
We believe that the decreased household air pollution levels including $\mathrm{PM}_{2.5}$ concentrations in gas stove kitchens may be the reason for the better respiratory and eye health symptoms. However, the crosssectional nature of our study, small number of study participants, and non-significant findings regarding respiratory symptoms highlight the need for cautious interpretation as well as future longitudinal and intervention studies.

According to a recent estimation of the World Health Organization, household air pollution caused 3.8 million deaths in year 2016, globally [25]. Although the proportion of the population using solid fuel is decreasing, still $41 \%$ of the global population are using coal, wood, charcoal, dung, crop residues, and kerosene as their primary fuels [1]. Due to accumulating levels of evidence on adverse health effects of household air pollution, transition from solid fuels to cleaner fuels such as gas and electricity may avert the deaths of millions of lives.

Nepal is one of the poorest countries in the world showing rapid increase of non-communicable disease, which accounts for more than $44 \%$ of mortality and $80 \%$ of outpatient visits [26]. Routine health examination and early treatment of the non-communicable disease are crucial for the disease management, but the primary prevention, by avoiding modifiable risk factors, would be a more realistic solution in view of the poor medical infrastructure and socioeconomic status of Nepal. Because particulate matter air pollution is second leading health risk factor in Nepalese [27], decreasing household air pollution levels by transition of solid fuels to cleaner fuels may be an important public health intervention. In our study, we found decreased household $\mathrm{PM}_{2.5}$ concentrations and improved watery eye symptoms in rural housewives using gas stoves compared to those in housewives using traditional stoves. Although not significant, a marked decrease was observed in the risk of chronic respiratory symptoms in gas stove users. The recent national sample survey of Nepal showed that about $88 \%$ of households uses solid fuel (wood: $77.3 \%$; straw/shrubs/grass: $3.6 \%$; animal dung: $6.9 \%$ ) and $12 \%$ uses clean fuel (electricity: $0.6 \%$; LPG/natural gas/biogas: $11.5 \%$ ) for cooking in rural Nepal [3]. With the view of high prevalence rate of solid fuel use in rural Nepal and findings from our study, energy transition from using solid fuels to cleaner fuel may improve respiratory and eye health symptoms of rural Nepalese housewives.

COPD is a chronic respiratory disease characterized by airflow obstruction and lung parenchyma damage, which are not fully reversible [7, 24]. Exposure to cigarette smoke, occupational toxins, and household and ambient air pollution are known to be the major risk factors for COPD development [24]. Household air pollution, originates from burning of solid fuels, may cause inflammation and oxidative stress of the respiratory epithelial cells, leading to bronchiole obstruction and disruption of the lung functions [7]. Therefore, it is biologically plausible to explain the direction of risk estimates for chronic respiratory symptoms in gas stove users observed in our study, although the results were not significant.

Several studies reported adverse health effects of household air pollution on eye health including ocular irritation [28]. Because biomass gas contains diverse toxic chemicals which may irritate the eye, reduced risk of watery eye symptoms during cooking among gas stove users in our study is also an expected

Page 14/ 23 
result. In an intervention study in Guatemala, use of chimney stove was associated with reduced level of exhaled carbon monoxide levels and eye irritation symptoms among the study participants [29]. In a cross-sectional study in Pakistan, use of smoke-free stove with chimney was associated with reduced carbon monoxide concentration in the kitchen and of watery eye symptoms in housewives during cooking [30].

Studies in Nepal and other developing countries have suggested the possible association between eye disease and household air pollution. Not only irritation of the eye itself but also oxidative stress induced by toxic chemicals in the biomass gas may change the lens opacity [9]. In a cross-sectional study of 143 Nepalese women, use of biomass fuel was associated with nuclear cataract and change in nuclear color in the lens, compared to that in gas fuel users [10]. In a population-based study in India, the use of biomass fuel was associated with an increased risk of cataract in women [18]. In our study, we observed a decreased risk of eye disease history among gas stove users compared to that among traditional stove users. However, cautious interpretation is needed due to the statistically insignificant results and the absence of detailed information regarding eye disease history.

Intervention studies in developing countries showed respiratory health benefits after reducing household air pollution levels [31]. By decreasing household air pollution levels through chimney wood stove installation, reduced respiratory symptoms were observed in Mexico and Guatemala [32, 33]. In a nonrandomized intervention study in Nepal, improved cough, phlegm, headaches, chest wheezing, and eye irritation symptoms were observed in 36 housewives who changed from the use of traditional to improved cook stove [34].

Other observational studies in developing countries including Nepal showed association between respiratory health and types of stove and fuel use. In a cross-sectional study of 1,392 rural Nepalese participants, use of biomass fuels was associated with increased risk of air flow obstruction compared to gas fuel users [35]. In a hospital-based case-control study with 606 lung cancer patients and 606 healthy controls in Nepal, household air pollution exposure from burning wood, charcoal, agricultural waste, and dung was associated with increased lung cancer risk [36]. In a cross-sectional study of 841 rural Mexican non-smoking women, use of biomass fuel was associated with increased risk of phlegm, coughing with phlegm, wheezing in the past, and FEV1/FVC ratio below 70\%, compared to gas fuel users [14]. By analyzing two waves of China family panel study and nine waves of China health and nutrition survey data, use of LPG was associated with lower risk of recent (1 month) physical discomfort (disease not specified) and better self-rated health scores [37].

Although statistically insignificant, we found clear reduction in risk estimates of chronic respiratory symptoms in gas stove users compared to that in traditional stove users. However, the risk of mild to severe obstruction on spirometry test did not show any difference between the types of stove use. Similar results were also observed in several studies [14], and further studies are needed to evaluate whether the exposure to smokes from burning solid fuels are more likely to affect chronic respiratory symptoms instead of airflow obstruction state in spirometer test. 
One of the possible explanations for this phenomenon may be the existence of secondary and tertiary stoves in studied households (shown in Additional file 6). Among the 90 study participants, about $60 \%$ had a secondary stove and $9 \%$ had a tertiary stove in their kitchen. People using traditional stoves as the primary stove tend to have a gas stove as their secondary stove, and people with gas stoves tend to have a traditional stove as their secondary stove. Because we only focused on primary stoves in our study, the existence of secondary and tertiary stoves may lead to misclassification bias, which may shift our effect estimates toward the null in this case.

Reasons for the high prevalence rate of COPD in rural Nepalese encompass poverty, high reliance on solid fuels, use of traditional stove, illiteracy, and poor use of medical facilities [4]. However, evidences remain limited regarding the health benefits of use of gas fuels instead of solid fuels [38]. Therefore, welldesigned longitudinal and intervention studies are needed in the future. In addition, we also observed low household income and high illiteracy rate in our study participants (Table 1). Although LPG/LNG and electricity were widely available in our study site, study participants were using solid fuels as their primary fuel due to the economic cost and convenience (shown in Additional file 5). Therefore, future intervention study should focus on not only the significant health benefits of changing traditional stoves to gas stoves, but also on cost-effective intervention methods, which may lead to sustainable use of clean energy fuels in the local community of rural Nepal. In addition, effective educational materials regarding adverse health effects of household air pollution as well as gas stove manuals for illiterate people are needed.

Our study has several limitations. First, because of the study design, we were only able to evaluate crosssectional association. Further longitudinal and intervention studies are crucial to confirming the causal association between types of stove used in households, and respiratory and watery eye symptoms in housewives residing in rural Nepal. Second, adverse health effects of traditional stove may be over estimated by the higher smoking rates of traditional stove users. Although we adjusted for the current smoking status, second-hand smoking status, and average years of smoking in the analysis model, cautious interpretation is needed. In addition, we did not have detailed information regarding the amount of cigarettes smoked per day. However, in sensitivity analysis, by restricting our study population to nonsmokers, we found similar results with our main analysis results. Third, because our study was conducted in only one rural village of Nepal with a relatively small number of study participants, similar studies in different regions of Nepal with larger numbers of study participants are needed to generalize our study findings. The small sample size in our study seems to have led to statistically insignificant results, although effect sizes were strong and directions are biologically plausible. Fourth, because our study was conducted during the summer season, we were unable to capture seasonal changes in household $\mathrm{PM}_{2.5}$ concentrations, and other seasonal factors associated with household $\mathrm{PM}_{2.5}$ concentrations. In addition, because we did not measure the outdoor $\mathrm{PM}_{2.5}$ concentration, we were unable to adjust for the effects of ambient $\mathrm{PM}_{2.5}$ on household $\mathrm{PM}_{2.5}$ concentration levels. However, most of the study participants had never changed their cooking stoves in the past, and the study participants' houses were concentrated in a single mountain village, located far away from main roads or 
factories. Therefore, the effects of ambient $\mathrm{PM}_{2.5}$ concentration on kitchen $\mathrm{PM}_{2.5}$ concentration may be minimal and may not differ by the types of cooking stoves. In addition, the 24-hour average $\mathrm{PM}_{2.5}$ concentrations of each household were relatively low (mean $22 \mu \mathrm{g} / \mathrm{m}^{3}$ ) compared to the ambient $\mathrm{PM}_{2.5}$ concentration in Nepal, estimated by the Global Burden of Disease research group $\left(100 \mu \mathrm{g} / \mathrm{m}^{3}\right.$ in year 2017) [27], which suggests minimal influence of the ambient $P_{2.5}$ concentration. Furthermore, distinctively increasing patterns of $\mathrm{PM}_{2.5}$ concentration have been observed between 5 and $9 \mathrm{AM}$ and between 5 and 8 PM, which suggests the existence of particular factors other than ambient air pollution. Lastly, although we measured the kitchen size, window size, door size, and time activity patterns of the study participants, we were unable to use the data due to the coding errors regarding the units of measures.

\section{Conclusion}

In conclusion, gas stove use was associated with a decreased risk of watery eye symptoms in our study. Although we observed a decreased risk of respiratory symptoms among gas stove users compared to that among traditional stove users, the results were not significant. Gas stove use may be beneficial for reducing chronic respiratory symptoms and eye discomfort, but the cross-sectional nature, small number of study participants, and statistically non-significant findings regarding respiratory symptoms in our study highlight the need for future longitudinal and intervention studies.

\section{Abbreviations}

$\mathrm{PM}_{2.5}$ : particulate matter less than $2.5 \mu \mathrm{m}$ in diameter; COPD: chronic obstructive pulmonary disease; ORs: odds ratios

\section{Declarations}

\section{Ethics approval and consent to participate}

Written and informed consent was obtained from all individual participants included in the study. The Institutional Review Committee of Kathmandu University School of Medical Sciences/Dhulikehl Hospital (approval number: 84/18) and the Nepal Health Research Council Ethical Review Board (reg.no. $251 / 2018$ ) approved this study.

\section{Consent for publication}

Not applicable

\section{Availability of data and materials}

The datasets generated and/or analyzed during the study are not publically available as institutional permission is required, but are available from the corresponding author upon reasonable request. 


\section{Competing interests}

The authors declare that they have no competing interests.

\section{Funding}

This research was supported by Science and Technology Support Program through the National Research Foundation of Korea (NRF) funded by the Ministry of Science and ICT (MSIT) (grant number: 2018K1A3A9A01000013). The funders had no role in the study design, data collection and analysis, decision to publish, or preparation of the manuscript.

\section{Authors' contributions}

Conceptualization, C.H., Y-C.H., B.K.; methodology, C.H., P.S., W-S.L., W-S.K.; software, C.H. and P.S.; validation, C.H., W-S.L., W-S.K.; formal analysis, C.H.; data curation, C.H., W-S.L., W-S.K., P.S., B.N., and S.S.; writing-original draft preparation, C.H.; writing-review and editing, C.H. and Y-C.H.; supervision, YC.H. and B.K.; project administration, Y-C.H., B.K., and S.S.; funding acquisition, Y-C.H.. All authors have read and agreed to the published version of the manuscript.

\section{Acknowledgement}

We thank all the study participants and research assistants.

\section{References}

1. World Health Organization: Exposure to household air pollution for 2016. Version 5. April 2018 (http://www.who.int/airpollution/data/HAP_exposure_results_final.pdf, assessed 2 June 2018). 2018.

2. World Health Organization: WHO guidelines for indoor air quality: household fuel combustion: World Health Organization; 2014.

3. Ministry of Health Nepal: Nepal Demographic and Health Survey 2016. Kathmandu, Nepal: Ministry of Health, Nepal. In.; 2017.

4. Bolton CE, Binaya K, Koju R, Hall IP: Challenges of chronic obstructive pulmonary disease in rural Nepal. The Lancet Respiratory Medicine 2019, 7(6):476-478.

5. Bhandari GP, Angdembe MR, Dhimal M, Neupane S, Bhusal C: State of non-communicable diseases in Nepal. BMC public health 2014, 14(1):23.

6. Roth GA, Abate D, Abate KH, Abay SM, Abbafati C, Abbasi N, Abbastabar H, Abd-Allah F, Abdela J, Abdelalim A: Global, regional, and national age-sex-specific mortality for 282 causes of death in 195 countries and territories, 1980-2017: a systematic analysis for the Global Burden of Disease Study 2017. The Lancet 2018, 392(10159):1736-1788. 
7. Silva $\mathrm{R}$, Oyarzún $\mathrm{M}$, Olloquequi $\mathrm{J}$ : Pathogenic mechanisms in chronic obstructive pulmonary disease due to biomass smoke exposure. Archivos de Bronconeumología (English Edition) 2015, 51(6):285292.

8. Smith KR, Bruce N, Balakrishnan K, Adair-Rohani H, Balmes J, Chafe Z, Dherani M, Hosgood HD, Mehta S, Pope D: Millions dead: how do we know and what does it mean? Methods used in the comparative risk assessment of household air pollution. Annual review of public health 2014, 35:185-206.

9. Shalini V, Luthra M, Srinivas L, Rao SH, Basti S, Reddy M, Balasubramanian D: Oxidative damage to the eye lens caused by cigarette smoke and fuel smoke condensates. Indian journal of biochemistry \& biophysics 1994, 31(4):261-266.

10. Pokhrel AK, Bates MN, Shrestha SP, Bailey IL, DiMartino RB, Smith KR, Joshi N: Biomass stoves and lens opacity and cataract in Nepalese women. Optometry and vision science: official publication of the American Academy of Optometry 2013, 90(3):257.

11. Sapkota Y, Hans L: Epidemiology of Blindness in Nepal: 2012; 2013.

12. Kurmi OP, Semple S, Simkhada P, Smith WCS, Ayres JG: COPD and chronic bronchitis risk of indoor air pollution from solid fuel: a systematic review and meta-analysis. Thorax 2010, 65(3):221-228.

13. Pratali L, Marinoni A, Cogo A, Ujka K, Gilardoni S, Bernardi E, Bonasoni P, Bruno RM, Bastiani L, Vuillermoz E: Indoor air pollution exposure effects on lung and cardiovascular health in the High Himalayas, Nepal: An observational study. European journal of internal medicine 2019, 61:81-87.

14. Regalado J, Pérez-Padilla R, Sansores R, Paramo Ramirez JI, Brauer M, Paré P, Vedal S: The effect of biomass burning on respiratory symptoms and lung function in rural Mexican women. American journal of respiratory and critical care medicine 2006, 174(8):901-905.

15. Ranabhat CL, Kim C-B, Kim C-S, Jha N, Deepak K, Connel FA: Consequence of indoor air pollution in rural area of Nepal: a simplified measurement approach. Frontiers in Public Health 2015, 3:5.

16. Pokhrel AK, Bates MN, Acharya J, Valentiner-Branth P, Chandyo RK, Shrestha PS, Raut AK, Smith KR: PM2. 5 in household kitchens of Bhaktapur, Nepal, using four different cooking fuels. Atmospheric Environment 2015, 113:159-168.

17. Norboo T, Yahya M, Bruce N, Heady J, Ball K: Domestic pollution and respiratory illness in a Himalayan village. International Journal of Epidemiology 1991, 20(3):749-757.

18. Ravilla TD, Gupta S, Ravindran RD, Vashist P, Krishnan T, Maraini G, Chakravarthy U, Fletcher AE: Use of cooking fuels and cataract in a population-based study: the India Eye Disease Study. Environmental health perspectives 2016, 124(12):1857-1862.

19. Miller MR, Hankinson J, Brusasco V, Burgos F, Casaburi R, Coates A, Crapo R, Enright Pv, Van Der Grinten C, Gustafsson P: Standardisation of spirometry. European respiratory journal 2005, 26(2):319-338.

20. Ferris BG: Epidemiology Standardization Project (American Thoracic Society). The American review of respiratory disease 1978, 118(6 Pt 2):1-120. 
21. Jones P, Harding G, Berry P, Wiklund I, Chen W, Leidy NK: Development and first validation of the COPD Assessment Test. European Respiratory Journal 2009, 34(3):648-654.

22. Balakrishnan K, Mehta S, Kumar P, Ramaswamy P, Sambandam S, Kumar KS, Smith KR: Indoor air pollution associated with household fuel use in India: an exposure assessment and modeling exercise in rural districts of Andhra Pradesh, India. 2004.

23. Karmacharya BM, Koju RP, LoGerfo JP, Chan KCG, Mokdad AH, Shrestha A, Sotoodehnia N, Fitzpatrick AL: Awareness, treatment and control of hypertension in Nepal: findings from the Dhulikhel Heart Study. Heart Asia 2017, 9(1):1-8.

24. Pauwels RA, Buist AS, Calverley PM, Jenkins CR, Hurd SS: Global strategy for the diagnosis, management, and prevention of chronic obstructive pulmonary disease: NHLBI/WHO Global Initiative for Chronic Obstructive Lung Disease (GOLD) Workshop summary. American journal of respiratory and critical care medicine 2001, 163(5):1256-1276.

25. World Health Organization: Burden of disease from household air pollution for 2016 (http://apps.who.int/gho/data/node.main.BODHOUSEHOLDAIRDTHS?lang=en, assessed 2 June 2018). 2018.

26. Mishra SR, Neupane D, Bhandari PM, Khanal V, Kallestrup P: Burgeoning burden of noncommunicable diseases in Nepal: a scoping review. Globalization and health 2015, 11(1):32.

27. Global Burden of Disease Collaborative Network: Global Burden of Disease Study 2017 (GBD 2017) Results. Seattle, United States: Institute for Health Metrics and Evaluation (IHME), 2018. Available from http://ghdx.healthdata.org/gbd-results-tool. 2018.

28. West S, Bates M, Lee J, Schaumberg D, Lee D, Adair-Rohani H, Chen D, Araj H: Is household air pollution a risk factor for eye disease? International journal of environmental research and public health 2013, 10(11):5378-5398.

29. Diaz E, Smith-Sivertsen T, Pope D, Lie RT, Diaz A, McCracken J, Arana B, Smith KR, Bruce N: Eye discomfort, headache and back pain among Mayan Guatemalan women taking part in a randomised stove intervention trial. Journal of Epidemiology \& Community Health 2007, 61(1):74-79.

30. Khushk WA, Fatmi Z, White F, Kadir MM: Health and social impacts of improved stoves on rural women: a pilot intervention in Sindh, Pakistan. Indoor air 2005, 15(5):311-316.

31. Gordon SB, Bruce NG, Grigg J, Hibberd PL, Kurmi OP, Lam K-bH, Mortimer K, Asante KP, Balakrishnan $\mathrm{K}$, Balmes $\mathrm{J}$ : Respiratory risks from household air pollution in low and middle income countries. The Lancet Respiratory Medicine 2014, 2(10):823-860.

32. Smith-Sivertsen T, Diaz E, Pope D, Lie RT, Diaz A, McCracken J, Bakke P, Arana B, Smith KR, Bruce N: Effect of reducing indoor air pollution on women's respiratory symptoms and lung function: the RESPIRE Randomized Trial, Guatemala. American journal of epidemiology 2009, 170(2):211-220.

33. Romieu I, Riojas-Rodriguez H, Marron-Mares AT, Schilmann A, Perez-Padilla R, Masera O: Improved biomass stove intervention in rural Mexico: impact on the respiratory health of women. American journal of respiratory and critical care medicine 2009, 180(7):649-656. 
34. Singh A, Tuladhar B, Bajracharya K, Pillarisetti A: Assessment of effectiveness of improved cook stoves in reducing indoor air pollution and improving health in Nepal. Energy for sustainable development 2012, 16(4):406-414.

35. Kurmi OP, Devereux GS, Smith WCS, Semple S, Steiner MF, Simkhada P, Lam K-BH, Ayres JG: Reduced lung function due to biomass smoke exposure in young adults in rural Nepal. European Respiratory Journal 2013, 41(1):25-30.

36. Raspanti GA, Hashibe M, Siwakoti B, Wei M, Thakur BK, Pun CB, Al-Temimi M, Lee Y-CA, Sapkota A: Household air pollution and lung cancer risk among never-smokers in Nepal. Environmental research 2016, 147:141-145.

37. Nie P, Sousa-Poza A, Xue J: Fuel for Life: Domestic Cooking Fuels and Women's Health in Rural China. International journal of environmental research and public health 2016, 13(8).

38. Fandiño-Del-Rio M, Goodman D, Kephart JL, Miele CH, Williams KN, Moazzami M, Fung EC, Koehler $K$, Davila-Roman VG, Lee KA: Effects of a liquefied petroleum gas stove intervention on pollutant exposure and adult cardiopulmonary outcomes (CHAP): study protocol for a randomized controlled trial. Trials 2017, 18(1):518.

\section{Figures}




\section{Traditional Stove}

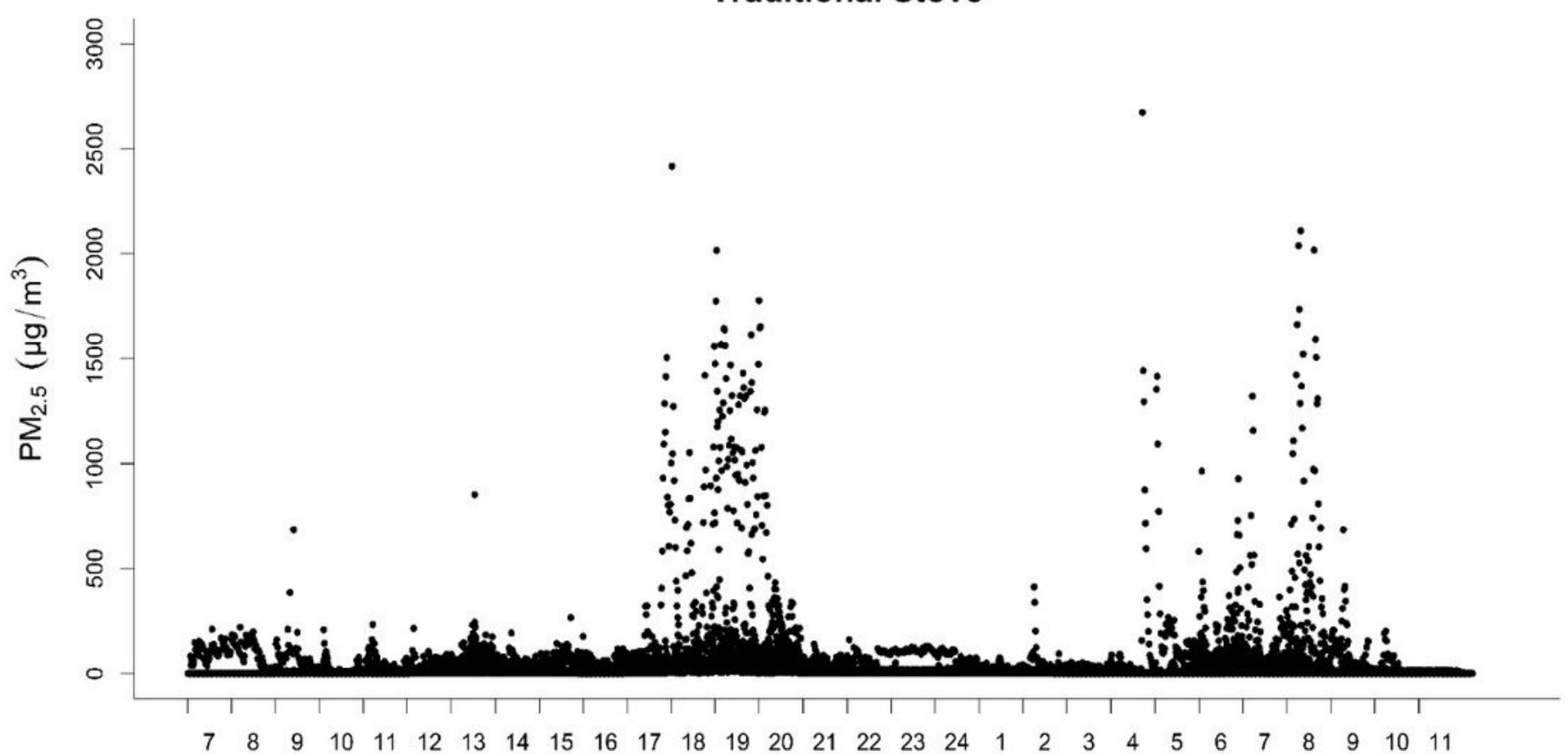

\section{Gas Stove}

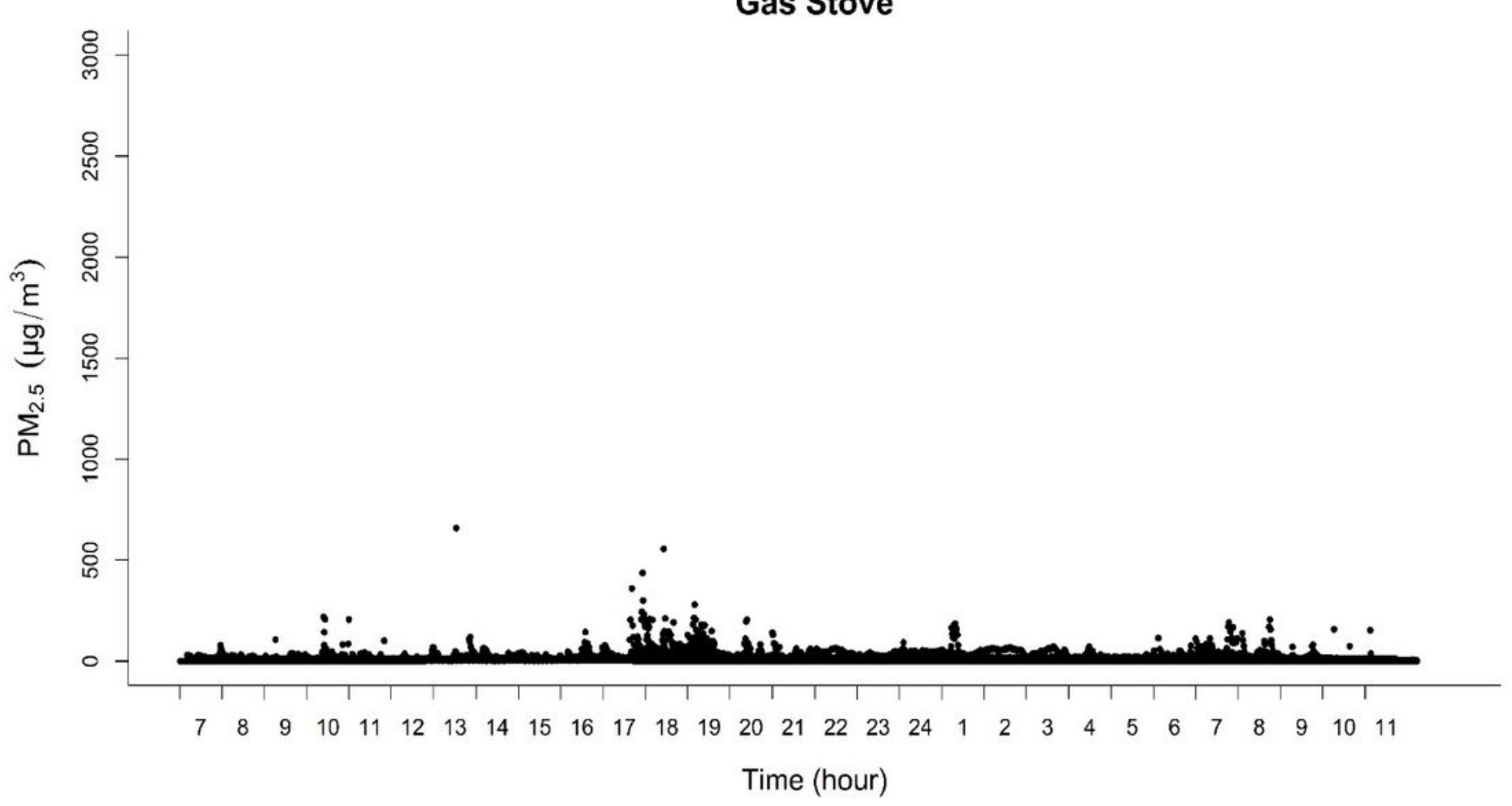

Figure 1

24 hour PM2.5 concentration patterns by types of household stoves (Traditional: 13 households, Gas: 16 households)

Supplementary Files 
This is a list of supplementary files associated with this preprint. Click to download.

- Additionalfile6.docx

- Additionalfile5.docx

- Additionalfile4.docx

- Additionalfile3.docx

- Additionalfile2.docx

- Additionalfile1.docx 